\title{
Silica-Zirconia Coatings Produced by Dipping and EPD from Colloidal Sol-Gel Suspensions
}

\author{
Y. CASTRO, B. FERRARI, R. MORENO AND A. DURÁN \\ Instituto de Cerámica y Vidrio (CSIC), Campus de Cantoblanco, 28049 Madrid \\ castro@icv.csic.es \\ aduran@icv.csic.es \\ Received July 21, 2004; Accepted December 29, 2004
}

8 Abstract. $\mathrm{SiO}_{2}-\mathrm{ZrO}_{2}$ sols have been prepared via acid catalysis using a commercial colloidal suspension of zirco-

9 nia and two silica alkoxides; tetraethoxysilane (TEOS) and methyltriethoxysilane (MTES). Suspensions with 10, 15

10 and $25-\mathrm{mol} \%$ of $\mathrm{ZrO}_{2}$ were prepared. The stability of the suspensions was followed by rheological measurements

11 showing that the amount of water incorporated with the colloidal suspension is the factor that limits the maximum

$12 \mathrm{ZrO}_{2}$ content. Coatings have been prepared by dipping using the suspensions up to 25-mol\% $\mathrm{ZrO}_{2}$ onto glass-slides

13 at different withdrawal rates. EPD process has been used to prepare coatings onto stainless steel AISI 304 using

14 the suspension with $25-\mathrm{mol}_{\%} \mathrm{ZrO}_{2}$ at different $\mathrm{pHs}$. The parameters associated with the EPD process (current

15 density, electric field, potential and deposition time) have been evaluated. The critical thickness for a $\mathrm{ZrO}_{2}$ addition

16 of $25-\mathrm{mol} \%$ was $0.8 \mu \mathrm{m}$ and it increased for diminishing $\mathrm{ZrO}_{2}$ content.

17 Keywords: $\mathrm{SiO}_{2}-\mathrm{ZrO}_{2}$ coatings electrophoretic deposition, suspension

\section{1. Introduction}

19 The sol-gel process is considered a suitable method

20 to produce protective functional coatings onto differ-

21 ent metallic substrates. The low processing temperature

22 needed to densify the coatings is one of the most im-

23 portant advantages of this process since some metals

24 present structural changes with temperature that de-

25 grade the mechanical properties of the substrate and

26 promote corrosion.
A wide range of compositions has been prepared by sol-gel. However, the preparation of silica-zirconia coatings have aroused a particular interest due to their superior chemical resistance to alkaline attack $[1,2]$ and fracture toughness [3]. The main problem of preparing coatings of this composition is related to the amount of $\mathrm{ZrO}_{2}$ that can be incorporated, the difficulty to obtain homogeneous materials without phase separation [4] and the low critical thickness that can be achieved. There are several works that report the preparation of silica-zirconia films an the difficulty to obtain crack-free coatings thicker than $0.5 \mu \mathrm{m} \mathrm{[5-8]} \mathrm{in} \mathrm{a} \mathrm{single} \mathrm{layer.} \mathrm{This} \mathrm{fact}$ restricts the use of these coatings with protective purposes.

Some works have been developed using EPD process to obtain thick silica coatings onto stainless steel using either acid-catalysed sols containing colloidal particles, or basic-catalysed particulate sols. These works have demonstrated that the use of EPD process can increase the critical thickness of the coatings over that reached by dipping $[9,10]$.

The present work examines the preparation of $\mathrm{SiO}_{2}-\mathrm{ZrO}_{2}$ sols via acid catalysis containing up to $40 \%$ mol of colloidal $\mathrm{ZrO}_{2}$ to produce hybrid glass-like coatings onto steel substrates by EPD and dipping. The stability of the sols and the processing parameters involved in the preparation of sols and coatings by dipping and EPD have been studied. 


\section{Experimental}

Four compositions in the system $\mathrm{SiO}_{2}-\mathrm{ZrO}_{2}$ with 10 , 15, 25 and 40-mol\% $\mathrm{ZrO}_{2}$ were prepared via acid catalysis. Tetraethoxysilane (TEOS) and methyltriethoxysilane (MTES) were used as precursors of $\mathrm{SiO}_{2}$ and a commercial colloidal suspension of $\mathrm{ZrO}_{2}(\mathrm{Ny}-$ acol(ac), PQ-Corporation, $\mathrm{pH}=3.5$ ) as precursor of $\mathrm{ZrO}_{2}$. The suspensions were prepared by mixing TEOS and MTES with the corresponding amount of colloidal suspension of $\mathrm{ZrO}_{2}$ and adding concentrated $\mathrm{HCl}$ up to reach a $\mathrm{pH} 4$. Table 1 summarises the molar ratios fixed for the synthesis and the total concentration obtained for each composition.

The suspensions were diluted adding absolute ethanol between 120 to $200 \mathrm{~g} / \mathrm{l}$. In the following the compositions will be named as XZr n(m) g/l, where X is the $\mathrm{ZrO}_{2}$ content, $\mathrm{n}$ the total concentration of oxides and $(\mathrm{m})$ the particle concentration.

The $\mathrm{pH}$ of the $25 \mathrm{Zr}$ suspension was modified toward acidity and basicity adding $\mathrm{HCl}$ and tetramethylammonium hydroxide (TMAH), respectively.

The rheological characterisation of the suspensions was performed by measuring the viscosity with composition, concentration, and storage time, using a rotational rheometer (Haake, RS550, Germany) under controlled rate conditions at $25^{\circ} \mathrm{C}$. The shear rate was increased from 0 to $1000 \mathrm{~s}^{-1}$ in $5 \mathrm{~min}$, with $1 \mathrm{~min}$ at the maximum rate and decreasing again to 0 in $5 \mathrm{~min}$.

Coatings were deposited by dipping on glass substrates and stainless steel AISI 304 varying the withdrawal rates from 9 to $65 \mathrm{~cm} / \mathrm{min}$. Glass substrates were cleaned in ultrasonic bath with ethanol and the stainless steel with an alkaline solution (P3Emalan5668:P3Emalan0469, Miele, Germany).

EPD tests were carried out at current densities from 0.2 to $1.8 \mathrm{~mA} / \mathrm{cm}^{2}$ and deposition times up to $60 \mathrm{~min}$ by using a potentiostate/galvanostate (AMEL 551, UK) under galvanostatic conditions in order to maintain a constant electric field. Polished stainless steel AISI 304 was used as working electrode and graphite as counterelectrode. A low withdrawal rate was used to minimise the dipping contribution to the total thickness.

Coatings produced by either dipping or EPD were dried at room conditions and sintered at $525^{\circ} \mathrm{C}$ for $30 \mathrm{~min}$ in air.

The thickness of the coatings obtained on glass substrates was determined by profilometry (Talystep, Taylor Hobson, UK) while that of coatings onto stainless steel was calculated by gravimetry. Optical mi- croscopy (Zeiss, HP1, Geremany) was used to evaluate $\mathbf{1 0 6}$ defects and cracks in the coatings.

\section{Results and Discussion}

Homogeneous and translucent suspensions with a max- 109 imum amount of $25 \%$ mol $\mathrm{ZrO}_{2}$ were prepared via 110 acid catalysis. The suspension of $40 \% \mathrm{~mol} \mathrm{ZrO}_{2}$ gelled 111 quickly due to the excess of water added with colloidal 112 $\mathrm{ZrO}_{2}$ that produces the unstabilisation of the suspen- $\mathbf{1 1 3}$ sion. Therefore, the amount of water is the factor lim- $\mathbf{1 1 4}$ iting the $\mathrm{ZrO}_{2}$ particles content, which can be incorpo- 115 rated to the suspension. $\quad \mathbf{1 1 6}$

The evolution of the suspensions was followed $\mathbf{1 1 7}$ through viscosity measurements as a function of con- 118 centration, composition and time. Figure 1 shows the $\mathbf{1 1 9}$ evolution of viscosity with shear rate of $25 \mathrm{Zr}$ suspen- $\mathbf{1 2 0}$ sion with concentration $210(110) \mathrm{g} / \mathrm{l}$ as prepared and $\mathbf{1 2 1}$ after $268 \mathrm{~h}$ at $25^{\circ} \mathrm{C}$. The fresh suspension shows a $\mathbf{1 2 2}$ Newtonian behaviour with a viscosity of $5 \mathrm{mPa}$.s. Af- $\mathbf{1 2 3}$ ter $268 \mathrm{~h}$, the viscosity increases and the suspension $\mathbf{1 2 4}$ becomes thixotropic. The increment of viscosity is re- $\mathbf{1 2 5}$ lated to the evolution of the condensation reactions that $\mathbf{1 2 6}$ increase the cross-linking and the agglomeration of the $\mathbf{1 2 7}$ particles. A similar behaviour was observed for com- $\mathbf{1 2 8}$ positions $10 \mathrm{Zr}$ and $15 \mathrm{Zr}$.

In order to increase the stability of the suspensions $\mathbf{1 3 0}$ they were diluted with absolute ethanol up to $120 \mathrm{~g} / \mathrm{l}$. $\mathbf{1 3 1}$ Figure 2 plots the evolution of viscosity with time for 132 compositions $10 \mathrm{Zr}, 15 \mathrm{Zr}$ and $25 \mathrm{Zr}$ showing that the $\mathbf{1 3 3}$ stability decreases for increasing amounts of $\mathrm{ZrO}_{2}$ due

\section{4}

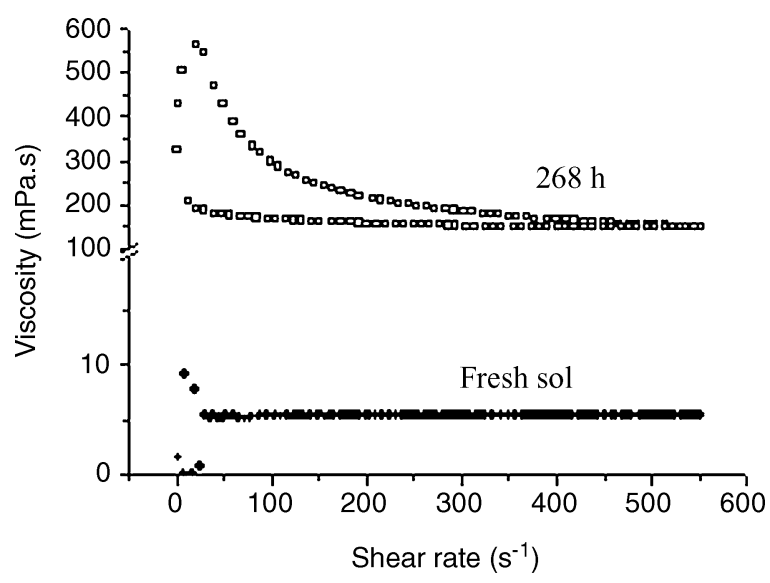

Figure 1. Evolution of the viscosity with the shear rate for the composition $75 \mathrm{Zr}$. 


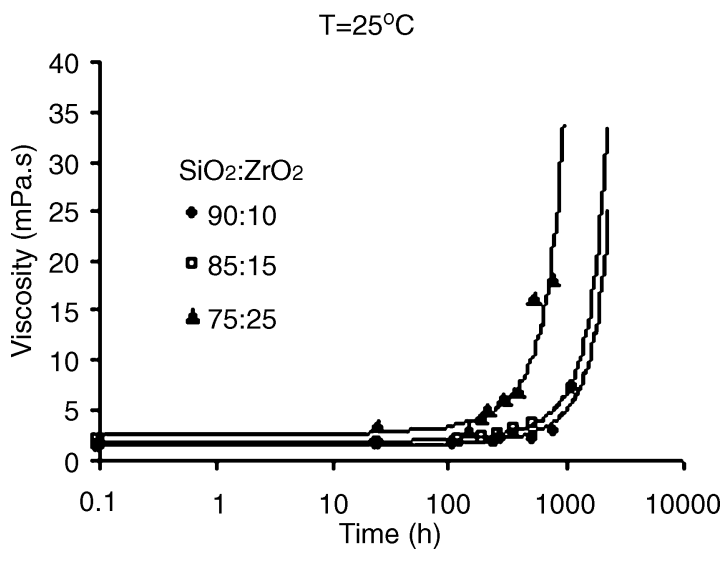

Figure 2. Stability of the $\mathrm{SiO}_{2}: \mathrm{ZrO}_{2}$ sols for concentration of $120(40) \mathrm{g} / \mathrm{l}$ at $25^{\circ} \mathrm{C}$.

$$
\left.\mathrm{ZrO}_{2} \sum^{-}+\mathrm{HO}-\mathrm{Si}-\mathrm{CH}_{3} \longrightarrow \mathrm{ZrO}_{2}\right)^{\mathrm{O}-\mathrm{Si}-\mathrm{CH}_{3}}
$$

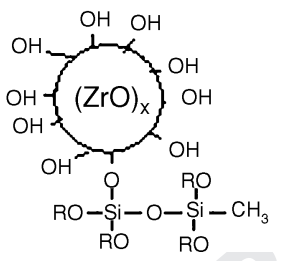

Figure 3. Structure of the $\mathrm{SiO}_{2}: \mathrm{ZrO}_{2}$ sols.

to the larger amount of water incorporated. The concentrated suspension $25 \mathrm{Zr}$ maintains stable for $100 \mathrm{~h}$, while the diluted one maintains stable over $190 \mathrm{~h}$.

A structure similar to that described by Mennig [11] is expected for these sols (Fig. 3), where $\mathrm{ZrO}_{2}$ particles are either linked by hydrolysed molecules of MTES and TEOS or covered by $\mathrm{OH}$ group or hydrolysed species.

Dipping tests were performed onto glass substrates using the suspensions $10 \mathrm{Zr}, 15 \mathrm{Zr}$ and $25 \mathrm{Zr}$ with concentrations of 282(53), 280(74) and 270(110) g/l, respectively, and varying the withdrawal rates up to $65 \mathrm{~cm} / \mathrm{min}$. Homogeneous and transparent coatings were obtained indicating a good dispersion of the particles. However, all the coatings cracked during drying. In order to determine the critical thickness $\left(e_{c}\right)$ of the coatings after sintering at $525^{\circ} \mathrm{C}$ the suspensions were diluted. Table 2 summarises the final concentration used to measure the dry and critical thickness $\left(e_{c}\right)$ for each suspension.

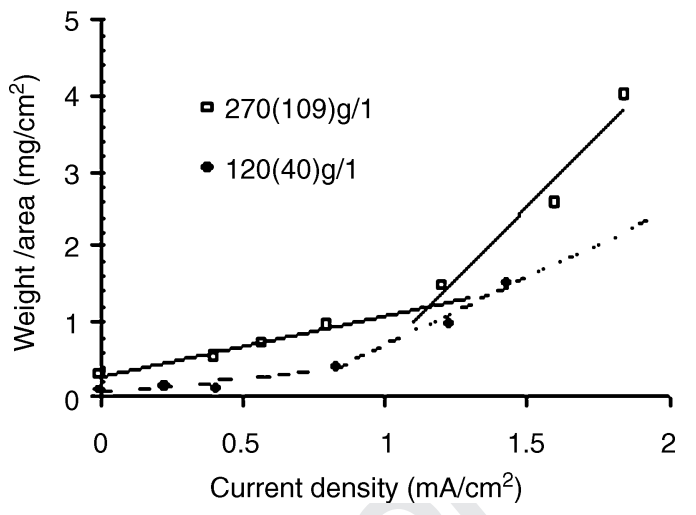

Figure 4. Deposited mass as a function of current density for the $75 \mathrm{Zr}$ sols with concentrations of 270(109) and 120(40) g/l.

The critical thickness decreases for increasing $\mathrm{ZrO}_{2} \quad 155$ particles content. This behaviour is usually observed $\mathbf{1 5 6}$ in systems of two oxides $\left(\mathrm{SiO}_{2}-\mathrm{B}_{2} \mathrm{O}_{3}[12,13], \mathrm{SiO}_{2}-157\right.$ $\mathrm{TiO}_{2}$ [14], $\mathrm{SiO}_{2}-\mathrm{ZrO}_{2}$ [2], etc.) and is related with the $\mathbf{1 5 8}$ appearing of high stresses, that generates cracks. In 159 the studied system $\mathrm{SiO}_{2}: \mathrm{ZrO}_{2}$ the internal stresses can 160 be more important due to the dense particles embed- 161 ded in the $\mathrm{SiO}_{2}$ network with very different expansion 162 coefficient.

163

The suspension $25 \mathrm{Zr}$ was selected to obtain EPD 164 coatings, since it has the highest content of $\mathrm{ZrO}_{2}$ with 165 adequate stability. A withdrawal rate of $3 \mathrm{~cm} / \mathrm{min}$ was 166 used to extract the substrate, in order to distinguish the $\mathbf{1 6 7}$ contribution of EPD respect to dipping. Figure 4 shows 168 the evolution of weight per unit area with the current 169 density for suspensions 270(110) g/l and 120(40) g/l $\mathbf{1 7 0}$ for a constant deposition time of $5 \mathrm{~min}$. A change of 171 slope is observed for both suspensions, as in other sol- 172 gel systems $[15,16]$. The deposition mass varies slowly $\mathbf{1 7 3}$ up to current densities of 1.2 and $0.8 \mathrm{~mA} / \mathrm{cm}^{2}$ for sus- $\mathbf{1 7 4}$ pensions 270(110) g/l and 120(40) g/l, respectively. 175 Above these values the deposition rate increases. $\mathbf{1 7 6}$

Homogeneous coatings were obtained using the con- 177 centrated suspension within a wide current density $\mathbf{1 7 8}$ range. In the case of diluted suspension (120(40) g/l), 179 homogeneous coatings were only obtained for cur- $\mathbf{1 8 0}$ rent densities lower than $0.8 \mathrm{~mA} / \mathrm{cm}^{2}$; for higher val- $\mathbf{1 8 1}$ ues, preferential deposition of the particles was de- $\mathbf{1 8 2}$ tected, leading to heterogeneous coatings. Maximum 183 dry thickness of $1 \mu \mathrm{m}$ and critical thickness of $0.8 \mu \mathrm{m} 184$ were reached with both suspensions. All the coatings 185 present a good adhesion to the substrate. $\quad \mathbf{1 8 6}$

In order to increase the thickness and the homo- 187 geneity of the coatings two aspects were considered. $\mathbf{1 8 8}$ 
First, the pH of the suspension 120(40) g/l was modified adding TMAH and $\mathrm{HCl}$ in order to increase the mobility of the particles. Second, the deposition kinetics was studied applying low current densities and long deposition times.

The modification of $\mathrm{pH}$ toward more basic region adding TMAH decreases the mobility of the particles because $\mathrm{pH}$ approaches to the isoelectric point of $\mathrm{ZrO}_{2}$. For this reason, the $\mathrm{pH}$ of the suspension was further modified by adding $\mathrm{HCl}$ up to values of 3.5 and 3 . In this case, the $\mathrm{ZrO}_{2}$ particles are positively charged and migrate toward the cathode under an electric field. Under this condition, no degradation of the substrate is expected. EPD tests were performed using the modified suspensions varying the current density between 0.38 and $1.4 \mathrm{~mA} / \mathrm{cm}^{2}$ for a constant deposition time of 5 min. Figure 5 shows the evolution of the deposition mass versus the current density for suspensions of $120(40) \mathrm{g} / \mathrm{l}$ with $\mathrm{pH} 3,3.5$ and 4 . The diminution of $\mathrm{pH}$ below 3.5 involves the increment of the viscosity and leads to a deviation from behaviour. The modification of $\mathrm{pH}$ seems to improve the dispersion of the particles, allowing to obtain homogeneous coatings from diluted suspensions, even at high current densities. However, the critical thickness maintains around $0.8 \mu \mathrm{m}$ after sintering.

The conductivity $(\sigma)$ of the suspensions has been calculated from the slope of the plot of electric field as a function of current density (Fig. 6). The conductivity increases for decreasing $\mathrm{pH}$. If the Hamaker's equation is considered (Eq. (1)), the increment of $\sigma$ should decrease the deposited mass, since $E=I / \sigma$ (where $I$ is the current intensity).

$m=C t A \mu_{e} E$

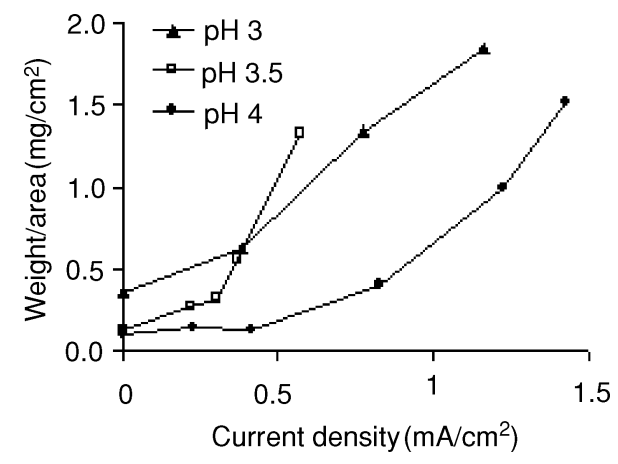

Figure 5. Weight per unit area vs. current density for $75 \mathrm{Zr}$ sols at different $\mathrm{pHs}$.

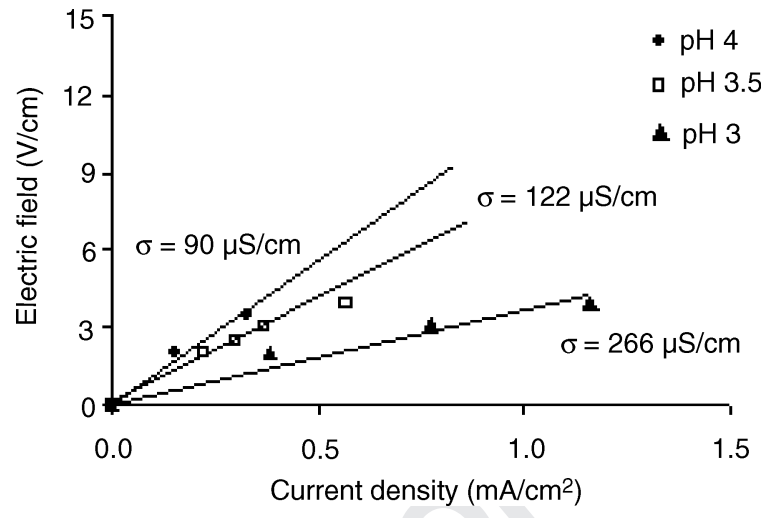

Figure 6. Evolution of the electric field with the current density for $75 \mathrm{Zr}$ sols at different $\mathrm{pHs}$.

( $m=$ deposition mass, $C=$ concentration, $t=222$ deposition time, $A=$ area, $\mu_{e}=$ electrophoretic mobil- $\mathbf{2 2 3}$ ity and $E=$ electric field).

However, Fig. 5 shows an increase of mass with de- 225 creasing $\mathrm{pH}$. This could be explained through a signif- $\mathbf{2 2 6}$ icant increase of the electrophoretic mobility, $\mu_{e}$, for $\mathbf{2 2 7}$ lowering $\mathrm{pH}$.

The deposition kinetics of the suspension 120(40) 229 $\mathrm{g} / \mathrm{l}$ at pH3 was studied at two current densities (Fig. 7). 230 For a current density of $0.55 \mathrm{~mA} / \mathrm{cm}^{2}$ the deposition 231 mass maintains constant for 2 min of deposition. Over 232 this time, the deposition rate increases quickly. In the 233 case of $0.77 \mathrm{~mA} / \mathrm{cm}^{2}$ an increment in the deposition $\mathbf{2 3 4}$ mass is observed from the beginning of the test. In 235 both cases, homogeneous coatings have been obtained. 236 However, neither the maximum dry thickness nor the $\mathbf{2 3 7}$ critical thickness was increased.

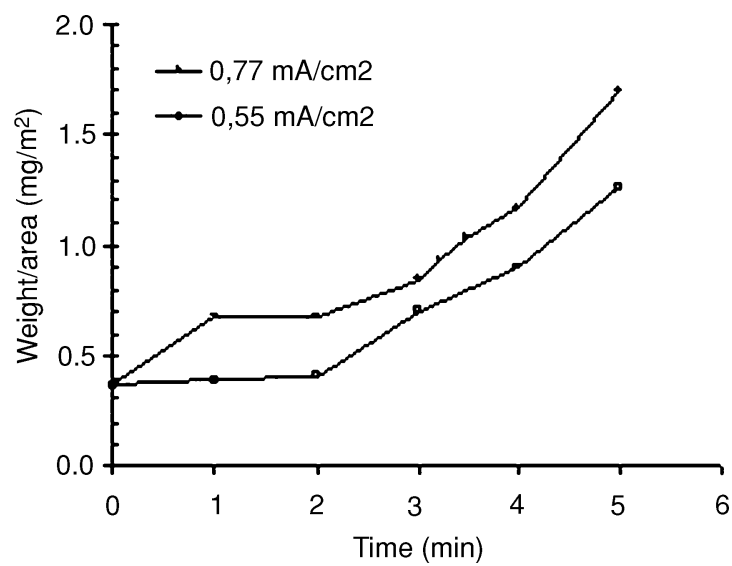

Figure 7. EPD kinetics at current densities of 0.55 and 0.77 $\mathrm{mA} / \mathrm{cm}^{2}$ for $25 \mathrm{Zr}$ sol at $\mathrm{pH} 3$. 
The modification of $\mathrm{pH}$ has allowed to improve the dispersion of the particles, although the viscosity of the suspensions is increased. On the other hand, the control of EPD parameters permitted to obtain homogeneous coatings using low deposition times. However, the problem of cracking during drying has not been solved; the maximum thickness of dry coatings was $1 \mu \mathrm{m}$ and it became $0.8 \mu \mathrm{m}$ after sintering at $525^{\circ} \mathrm{C}$.

Further work is in progress to study the increment of the thickness of $\mathrm{SiO}_{2}-\mathrm{ZrO}_{2}$ coatings by adding drying control chemical additives (DCCAs) such formamide, or binder/plasticizer, such polyethylenglicol (PEG), Polyvinylbutyral (PVB), etc.

\section{Conclusion}

Homogeneous and translucent $\mathrm{SiO}_{2}-\mathrm{ZrO}_{2}$ sols with a maximum amount of $25-\mathrm{mol} \% \mathrm{ZrO}_{2}$ were prepared via acid catalysis. The water content in the colloidal suspension limits the amount of $\mathrm{ZrO}_{2}$ which can be incorporated.

The dilution of the sols with ethanol improves their stability reducing the initial values of viscosity and avoiding the agglomeration of particles.

Homogeneous and transparent coatings with good adherence to glass and stainless steel have been prepared by dipping. Maximum dry coatings of $2 \mu \mathrm{m}$ and $1 \mu \mathrm{m}$ and critical thickness of 1.5 and $0.8 \mu \mathrm{m}$ have been obtained for $10 \mathrm{Zr}$ and $25 \mathrm{Zr}$ sols, respectively.

The modification of $\mathrm{pH}$ enhances the dispersion of the particles and allows to obtain homogeneous EPD coatings in short times using the diluted sols. EPD dry and critical thickness were similar to those obtained by dipping process.
Acknowledgments

This work has been supported by projects MAT2003- 272 05902-C02-01 (CICYT, Spain).

\section{References}

1. K. Izumi, M. Murakami, T. Deguchi, and A. Morita, J. Am. 275 Ceram. Soc. 72, 1465 (1989).

2. A.C. Lopez, J. Gallardo, and A. Durán, Bol. Soc. Ceram. Vidr. 277 40, 429 (2001).

3. M. Nogami and M. Tomozawa, J. Am. Ceram. Soc. 69, 99279 (1986).

4. J.M. Miranda Salvado and J.M. Fernández Navarro, J. Mater. 281 Sci. Lett. 9, 173 (1990). 282

5. Y. Lin and C. Jijian, J. Non-Cryst. Solids 112, $442 \mathbf{2 8 3}$ (1989).

6. P.C. Innocenzi, M. Guglielmi, M. Gobbin, and P. Colombo, J. 285 Eurp. Ceram. Soc. 10, 431 (1992).

7. M. Atik, C.R. Kha, P. De Lima Neto, L.A. Avaca, M.A. Aegerter, 287 and J. Zarzycki, J. Mater. Sci. Lett. 14, 178 (1995). 288

8. Y. Castro, M. Aparicio, and A. Durán, J. Sol-Gel Sci. Tech. 289 (sent).

9. Y. Castro, A. Durán, R. Moreno, and B. Ferrari, Adv. Mater. 14, 291 1505 (2002).

10. Y. Castro, B. Ferrari, R. Moreno, and A. Durán, J. Sol-Gel Sci. 293 Tech. 26, 1 (2003). 294

11. M. Mennig, G. Jonschker, and H. Schmid, SPIE Sol-Gel Optics. 295 1758(II), 125 (1992).

12. M.A. Villegas, M. Aparicio, and A. Durán, J. Non-Cryst. Solids 297 218, 146 (1997).

13. N. Tohge and T. Minami, J. Non-Cryst. Solids 112, 432299 (1989).

14. O. Martins and R.M. Almeida, J. Sol-Gel Sci. Technol. 19, 651301 (2000).

15. Y. Castro, B. Ferrari, A. Durán, and R. Moreno, J. Mater. Sci. 303 39, 845 (2003).

16. Y. Castro, B. Ferrari, R. Moreno, and A. Durán, Surf. Coat. 305 Techn. 182, 199 (2004). 